\title{
Thermal Fatigue Model of Aluminium Alloy Die Casting H-13 Dies under Thermo-Mechanical Cycle
}

\author{
Ghusoon Ridha MOHAMMED*, Ethar Mohammed MUBARAK**, Basim Hussein ABBAS*** \\ *Middle Technical University, Baghdad, Alzafaranya10074, Iraq, E-mail: ghusoon_ridha@yahoo.com \\ **Middle Technical University, Baghdad, Alzafaranya10074, Iraq, E-mail: etharmubarek25@gmail.com \\ ***Middle Technical University, Baghdad, Alzafaranya10074, Iraq, E-mail: basim.han1964@mtu.edu.iq \\ crossref http://dx.doi.org/10.5755/j02.mech.25765
}

\section{Introduction}

Industrial die casting is one of the most frequent causes of material failure under extreme temperature cycling of tool working surfaces; the properties of related material should thus be optimized. The properties of die casting materials may vary significantly for a given hardness depending on the heat treatment. Heat treatment critically affects the metallurgical properties of hot-work tool steels. Specific heat treatment systems allow for high quenching velocities, and they are available on the market. These systems include vacuum systems with high-pressure nitrogen or helium-quenching, and sophisticated dual-chamber vacuum systems [1,2]. During tool cycling, materials' behavior is determined by tool material properties and complex interaction between thermal cycling and mechanical conditions $[3,4]$. The resistance of material to tempering significantly depends on the heat treatment [5-7].

Many researchers have proposed different techniques for improving the material properties of die-casting dies in order to decrease heat-checking. To suppress cracking of grain boundaries, researchers have developed special grades of H-13 and H-11 steels and rapid quenching techniques. The developed materials and techniques showed improvement in hardness and toughness. Studies have also presented an advanced optimization software tool for heat treatment of tool steels based on pre-calculated data using finite elements (FE) [8-10]. Higher tempering resistance prevents rapid hardness loss, which contributes to thermal fatigue cracking on working surfaces of dies [11-13]. Empirical [3] and more sophisticated FE modeling approaches have been developed to optimize heat treatment of certain materials [13-15]. However, these techniques do not consider various factors of actual die casting conditions [10]. Thus, die failure must be prevented throughout the die life cycle, and it should be predicted for the development of new models that describes cyclic material response.

This paper focuses on the thermal fatigue model and prediction of cracking and die life under thermos-mechanical cycles. This model was used to establish the relationship between basic mechanical properties and thermal fatigue resistance. H13 tool steels were used as specimens, and their thermal fatigue responses were experimentally evaluated under thermal cycling at $700^{\circ} \mathrm{C}$. This paper describes in detail the apparatus and thermal fatigue specimens. Insights were also provided into the feasibility of using a combination of typical thermal fatigue theories and numerical models for life cycle prediction in materials die casting environments.

\section{Background of theory}

\subsection{Thermal die casting}

Die casting refers to the process of high volume production; it is used in manufacturing complex and geometrically non-ferrous material parts with thin walls and high flow-length-to-thickness ratio. The process is commonly used for batch sizes of 300,000 parts, reaching a production rate of 200 parts/h [16]. In the die casting industry, losses are attributed to failure and wearing of die, resulting in production loss and high cost due to die downtime. In the process, the most significant failures stem from soldering, chemical attack, corrosion, or thermal fatigue. Die casting results in cracks known as heat checks on the die surface. Heat checks cause deterioration of surface quality and their transmission over time cumulatively damages die [17]. During die casting cycles, thermal fatigue is caused by alternate cooling and heating of dies [18]. The profile shows that the heat gradient between the core and the surface leads to the compression and tension of the die steel surface in the course of heating and cooling, respectively.

\subsection{Thermal fatigue cracking in die-casting}

Thermal fatigue cracking is the major failure associated to hot-work tool steel dies in forging and die casting applications. Owing to the significant thermal shock in dies, crack forms as materials are heated rapidly to $700^{\circ} \mathrm{C}$, followed by quenching at $150^{\circ} \mathrm{Cusing}$ lubricant spray. The loading of thermal fatigue propagates cracking until the occurrence of cumulative damage or until the die becomes unusable. With limited cases of thermal fatigue, it is assumed that whole thermal strain transformed into mechanical strain. This case is the basis of most thermal fatigue theories which indicate that fixed bar exists at ends between two fixed plates; thus, the bar length must be kept constant [1923].

Under such circumstances, cracking only transpires as plastic strain occurs under both heating and cooling cycles, resulting in plastic strain accumulation in each cycle. Such conditions are sources of worry in die casting. Several mechanisms affect thermal cycle; heat gradient between core and surface limits thermal expansion. Thus, there is no complete transformation of heat strain into mechanical stress. While heating die surfaces, there is a transformation of some portions of thermal strain into mechanical stress due to heat gradient, and the rest arises from the surface $[5,24-$ 26]. The majority of materials display strain hardening, that is, stress increases gradually with strain after yielding. Due 
to the continuous changes in temperature, there is also a continuous change in the stress-strain relationship. Therefore, using only strain-stress curve cannot solve the proposed issue $[21,27]$. At the mean temperature of cycles, strainstress curve may be adopted as first approximation with expected error. Based on such effect, yielding occurs in specific directions (called compression), while plastic flow (called tension) decreases stress in opposite direction.

Changes are also observed in thermal and mechanical features of die materials after modifying time and temperature. After 1000 or 10000 cycles, the features differed from their initial states. Chemical erosion is another process for reducing heat stress resistance; oxidation and corrosion are types of chemical erosion [26]. Usually, material surface contacts with gases such as oxygen and this can induce chemical reactions with the materials. Brittle and weak molecules, such as oxides may generate in thermal stress test with high temperature, thereby modifying conduction of heat and other heat features [21, 24]. Then, fatigue test or thermal shock turns to a test of the resulting surface layer instead of original material. For the ideal heat cycle, the whole heat strain is transformed into plastic and elastic strain. Therefore, the plastic strain may be adopted for the prediction of cycle numbers into failure:

$$
N_{f}^{n} \varepsilon_{p}=C \varepsilon_{f}
$$

where: $N_{f}$ refers to cycle number at failures; $\varepsilon_{p}$ refers to plastic strain; $\varepsilon_{f}$ refers to true fracture deformation, which is the strain value of material failing in a cycle (also named coefficient of fatigue strength); $n$ and $C$ are constants. Nevertheless, not all heat strains are transformed into mechanical strain; some are modified on the surface [28].

$$
\begin{aligned}
& \varepsilon_{T}=\alpha \Delta T\left(\varepsilon_{e}+\varepsilon_{p}\right), \\
& \varepsilon_{e}=\frac{(1-v) \Delta \sigma}{E} .
\end{aligned}
$$

Replacing (3) in (2) we get:

$$
\varepsilon_{T}=\alpha \Delta T \frac{(1-v) \Delta \sigma}{E}+\varepsilon_{p} .
$$

By rearranging Eq. (4), one obtains:

$$
\varepsilon_{p}=\alpha \Delta T \frac{(1-v) \Delta \sigma}{E}-\varepsilon_{T}
$$

And replacing (5) in (1), we obtain:

$$
\begin{gathered}
N_{f}^{n}\left(\alpha \Delta T-\frac{(1-v) \Delta \sigma}{E}-\varepsilon_{T}\right)=C \Rightarrow \\
N_{f}^{n}=\frac{C \varepsilon f}{\left(\alpha \Delta T-\frac{(1-v) \Delta \sigma}{E}-\varepsilon_{T}\right)} .
\end{gathered}
$$

where: $\alpha \Delta T$ is total thermal strain; $\varepsilon_{T}$ is net thermal strain on surface, and $(1-v) \Delta \sigma / E$ is elastic strain [29]. lowing:

Coffin-Manson equation is used to obtain the fol-

$$
N_{f}=\left(\frac{C \varepsilon_{f}}{\left.\alpha \Delta T-\frac{(1-v) \Delta \sigma}{E}-\varepsilon_{T}\right)}\right)^{1 / n}
$$

Some limitations exist in this mathematical model (surface impurities, grain size, and defects acting as initiator; changing cycle number of failures are considered), and they will be improved with further research. Currently, the coefficient of heat transfer may change with varying cases. The contact of die with lubricant and molten metal generates an oxide layer that affects cracking mechanism. Currently, such mechanism cannot be considered in the proposed model [20].

\section{Materials and procedures}

\subsection{Materials}

Table 1 showed the investigated H13 steel and its chemical composition. The sample geometry was determined as follows: outer and inner diameter $33 \& 22 \mathrm{~mm}$ respectively, length $60 \mathrm{~mm}$. the sample geometry was determined using computer numerical control (CNC) turning and CNC milling machines. The sample dimensions and the fatigue testing machine are depicted in Figs. 1 and 2 respectively while Table 2 displayed the mechanical properties of the material.

Table 1

Chemical composition of AISI H13 tool steel

\begin{tabular}{|c|c|c|c|c|c|c|c|c|}
\hline $\mathrm{C}$ & $\mathrm{Mn}$ & $\mathrm{Si}$ & $\mathrm{Cr}$ & $\mathrm{Ni}$ & $\mathrm{Mo}$ & $\mathrm{V}$ & $\mathrm{Cu}$ & $\mathrm{S}$ \\
\hline 0.45 & 0.5 & 1.2 & 5.5 & 0.3 & 1.7 & 0.8 & 0.25 & 0.03 \\
\hline
\end{tabular}

Table 2

Mechanical properties of H13 tool steel

\begin{tabular}{|l|l|}
\hline Properties & AISI H13 \\
\hline Tensile strength Ultimate, MPa & 1590 \\
\hline Tensile strength,yield, MPa) & 1380 \\
\hline Modulus of elasticity, GPa & 215 \\
\hline Poison's ratio & 0.3 \\
\hline Hardness, HRC & 53 \\
\hline${\text { Thermal expansion } \alpha, \mathrm{m} / \mathrm{m} .{ }^{\circ} \mathrm{k}}^{\circ}$ & $13.5 \times 10^{-6}$ \\
\hline${\text { Thermal conductivity } k, \mathrm{w} / \mathrm{m} .{ }^{\circ} \mathrm{k}}^{\text {Reduction of area }}$ & 28.8 \\
\hline
\end{tabular}

\subsection{Thermal fatigue apparatus}

This research critically examined different steels under different surface and heat treatments of pressure die casting tools. The steels were investigated for metallurgical $\&$ mechanical properties. Thermal fatigue tests were also performed on the materials in a bid to determine the correlation between the basic mechanical properties of the materials, toughness, hardness, and thermal fatigue resistance. The thermal fatigue testing cycle lasted for $24 \mathrm{~s}$. The test specimens were immersed in molten aluminium alloy (Al 356) at $700^{\circ} \mathrm{C}$. Air was used to cool specimens for $5 \mathrm{sec}$ as 
they move in water-based lubricant bath after immersion for $7 \mathrm{sec}$. Then, the specimens were immersed in water at $32^{\circ} \mathrm{C}$ for $7 \mathrm{sec}$ to prevent aluminium from sticking to the test samples and generate heat gradient during cooling. Afterward, the samples were moved in air at $28^{\circ} \mathrm{C}$ in a cyclic manner between molten aluminium bath and water bath to achieve heat fatigue loading. Water at $32^{\circ} \mathrm{C}$ was used to constantly
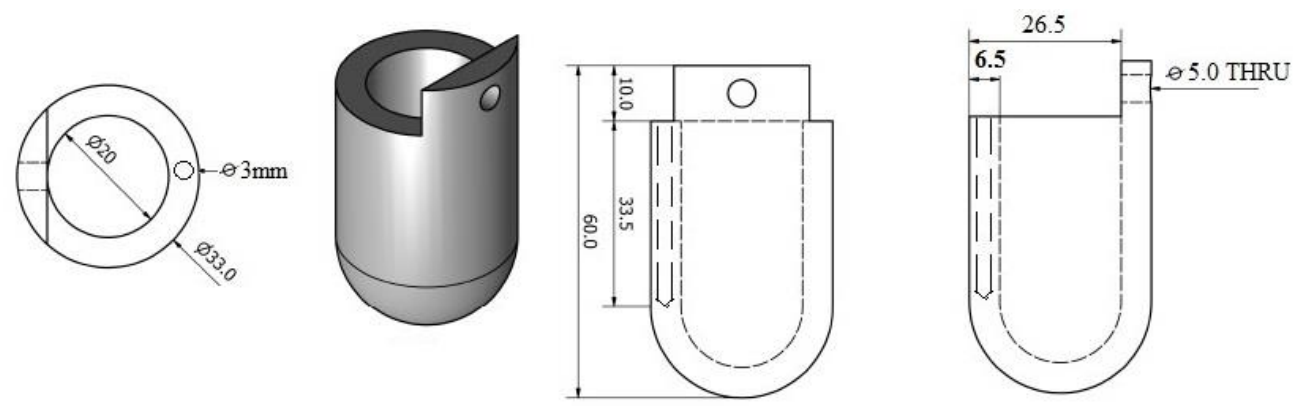

Fig. 1 Dimensions of Thermal fatigue sample

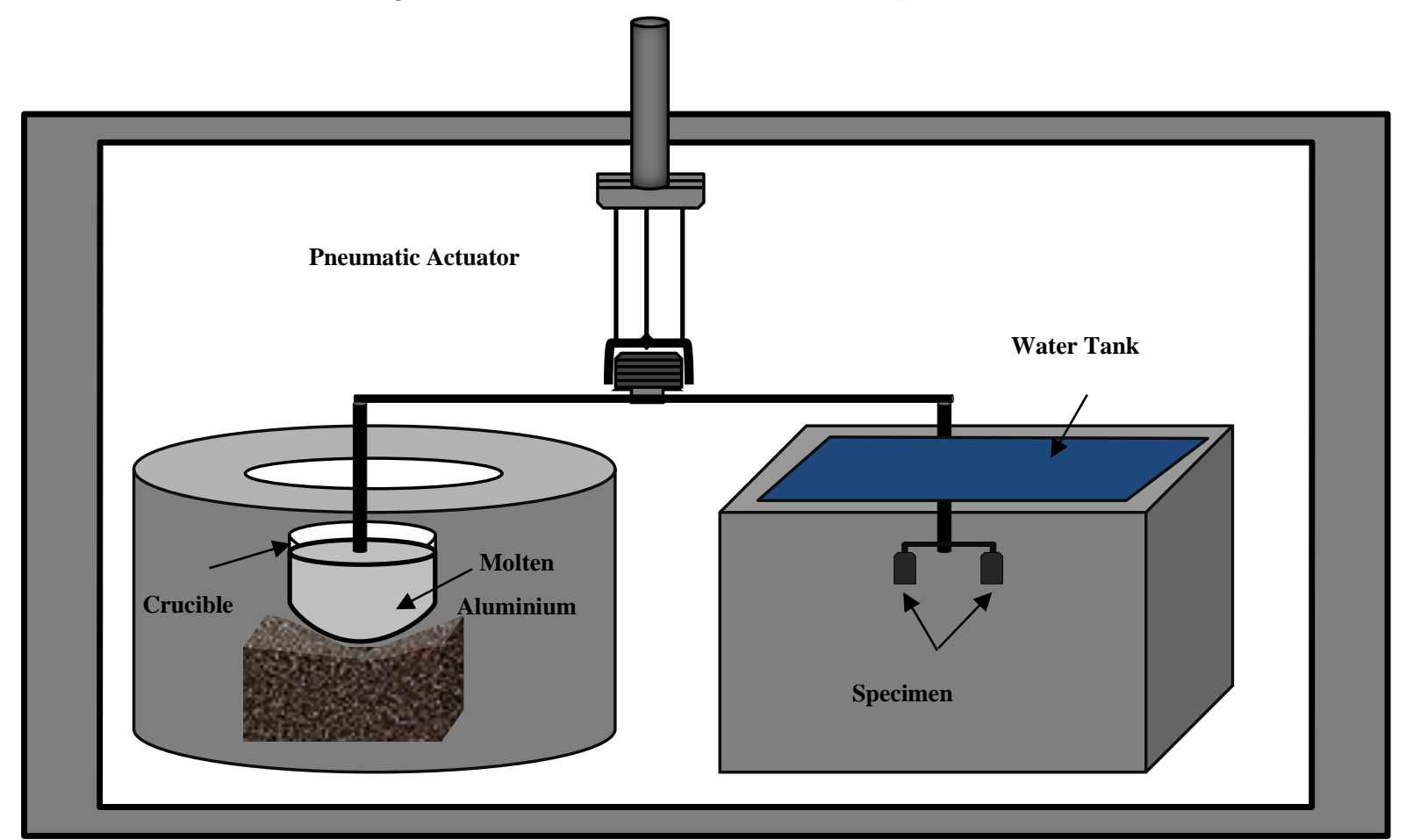

Fig. 2 Illustrated thermal fatigue test

\section{Simulation model}

The simulation study aimed at analysing the influence of parameters on the immersion test. Higher heat stresses increase thermal fatigue of materials, and lower heat stresses prolong the lifetime of in-service tools. ABAQUS software coupled with thermo-mechanical simulation was used to perform the immersion tests. A three-dimensional FE model was developed for the cross-section of the specimens. The specimens exhibit a geometrical symmetry in both axes. 1152 linear four-node elements (DC2D4) were used to model half of the cross-section as illustrated in Fig. 3. With load applied along xx-, yy-, and zz-axes and with increasing temperature, stress occurs, and molten aluminium alloy is formed. The heat flux per unit area is a consequence of the time-dependent increase in temperature between the two ends of the cylinder along $\mathrm{x}-, \mathrm{y}-$, and $\mathrm{z}$-axes for both steel and aluminium. cool the test samples internally. The measured temperature cycles in the samples were adopted for the following purposes: i) comparison of the intensities of heat gradients tested at critical points by virtue of pressure die casting material, and ii) calculation of the thermal stresses of the samples in one test cycle. 
comprises of 1152 two-dimensional plane strain elements (CPEG4) in which strain in $z$-axis equals zero $(c z z=0)$. Figs. $4 \mathrm{a}$ and $\mathrm{b}$ presented the temperature-dependent thermal expansion, specific heat, and thermal conductivity of $\mathrm{H} 13$ specimen used in the FE model.

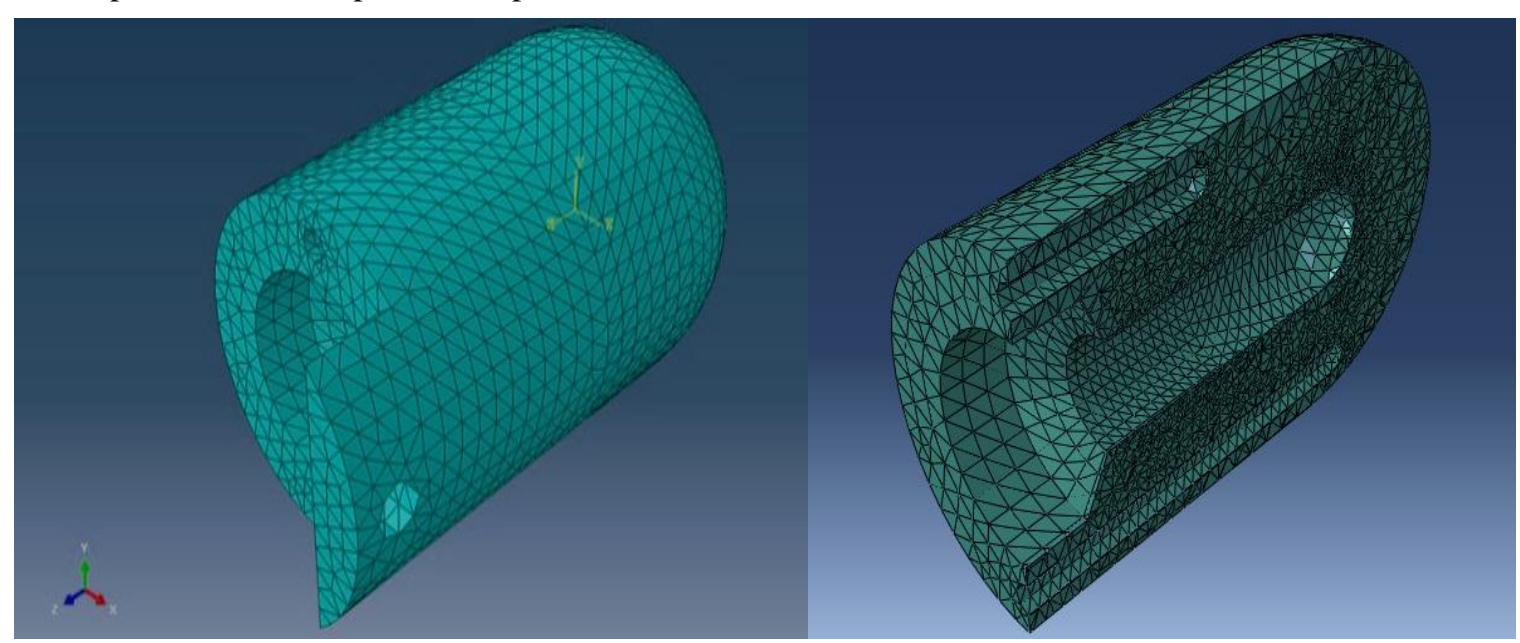

Fig. 3 Optimal test specimen's FE model

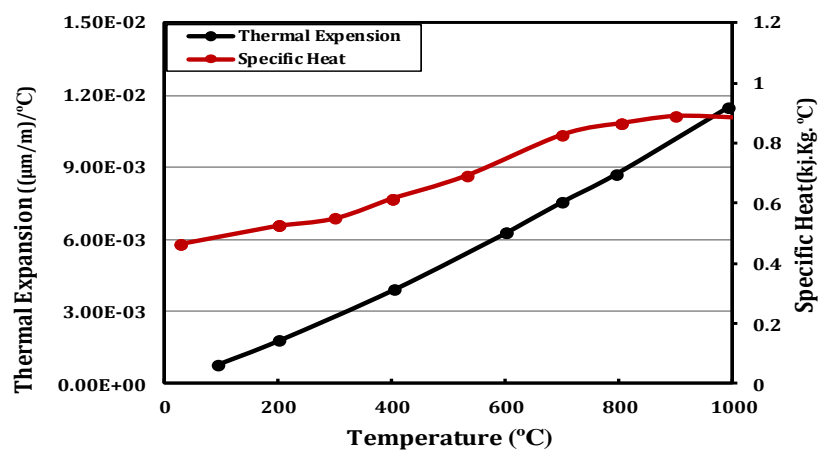

a

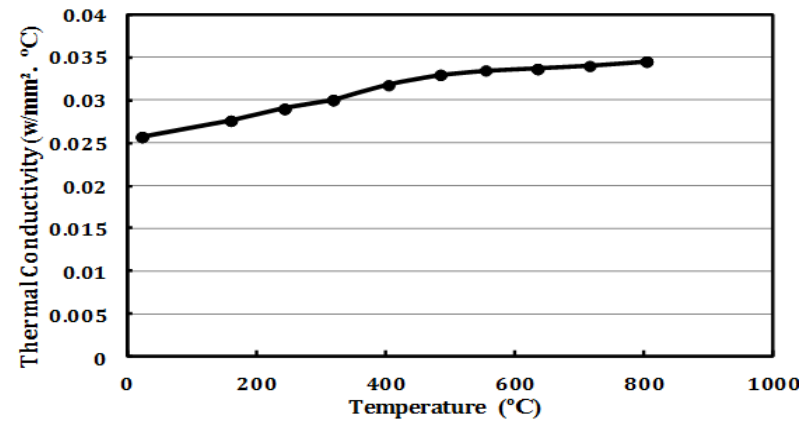

b

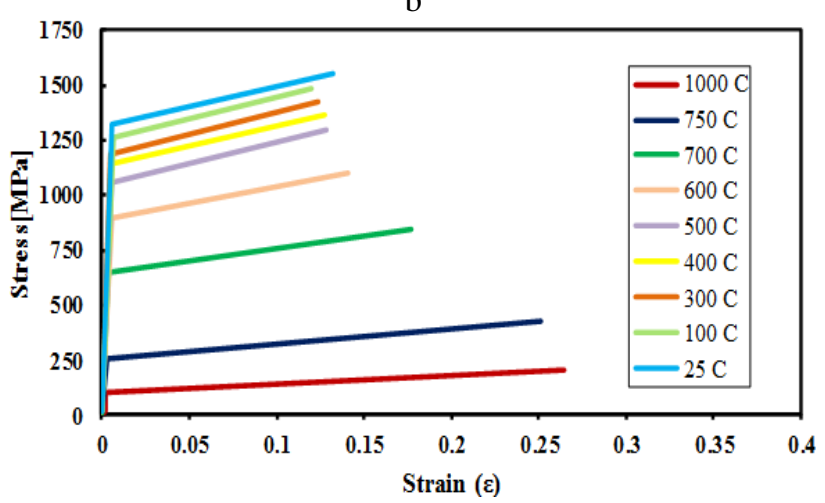

c

Fig. 4 Properties of H13 tool steel: a) specific heat and thermal expansion; b) thermal conductivity; c) stress and strain
Based on a plastic-elastic constitutive model, the strain-stress curve was constructed using maximum stress, elongation, elastic modulus, and yield stress. Therefore, the work hardening features of the materials were defined (Fig. 4, c). The strain-rate irrespective model was adopted, along with Von Misses-produces isotropic hardening criterion and Poisson's ratio of 0.3 . The analysis adopted the temperature-dependent coefficient of linear thermal expansion. The temperature was measured by thermocouples (TCs) which were inserted into $3 \mathrm{~mm}$ diameter holes drilled near the outer and inner sample surfaces. The Outer TC was positioned at the specimen with centreline from both outer surfaces. The specimens were prepared with two holes of 20 and $40 \mathrm{~mm}$ depth from the top. For the thermal cycle of H13 tool steel, the evaluation region covered the difference between 20 and $40 \mathrm{~mm}$ holes as measured from the top of the specimen

\subsection{FEM die modelling}

In Figs. 5, a and b, stress and temperature profiles were illustrated for the points described above. As shown in Fig. 5, a, the temperature profile resembles the one acquired in actual die casting between 120 and $700^{\circ} \mathrm{C}$. Fig. 5 showed the temperature and stress profiles (in the $\mathrm{X}$ direction) during cooling and higher core temperature compared with surface temperature. This condition transforms compressive stress to tensile stress. Fig. 5, b presented evidence of such change. During cooling, $255 \mathrm{MPa}$ tensile stresses occurred on the surface and after cooling, $138 \mathrm{MPa}$ residual tensile stresses were observed in the same area. A total of $317 \mathrm{MPa}$ compressive stresses were observed on the surface during heating, and tensile strain was also observed. These observations indicated that limitations caused by heat gradient were not as flawless as that of ideal heat cycle, and that heat stress occurs on the material surfaces. In the 2 nd simulation run, the temperature ranged from $115^{\circ} \mathrm{C}$ to $700^{\circ} \mathrm{C}$; this range was similar to that of plastic stress during heating. As observed, stress remained compressive during cooling because of insufficient heat gradient. 
By contrast, significant hardness loss was recorded as an immediate result of material softening. Clearly, hardness loss decreases plastic limit, and earlier plastic deformation results from lower hardness of materials as illustrated in Fig. 6. Higher hardness value prevents plastic deformation and ensures stable operation performance of materials in elastic area. This condition significantly increases the cycle number or die failure $[3,4,6]$. Though hardness decreases on surface, as recorded with oxidized samples, the measured data proved that surface-modified steels may maintain critically high levels of hardness in the 1 st $200 \mu \mathrm{m}$ to out-surface (150-410 HV $\mathrm{HV}_{\mathbf{0 . 5}}$ ) even after 3000 cycles of immersion. By contrast, cyclic immersion from steel surface to steel core results in decreases in hardness level of H13 steel (after 5000 cycles, < $350 \mathrm{HV}_{0.5}$ ).

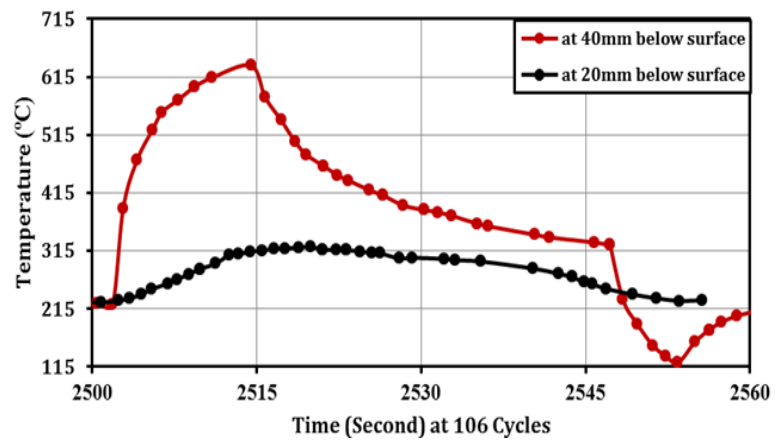

a

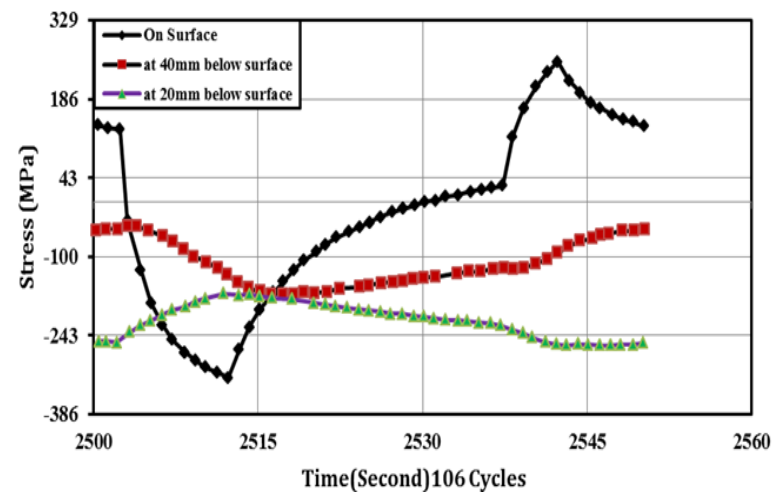

b

Fig. 5 FEM-calculated: a- temperature profile, b- stress profiles at different time points

Melt/steel interface induces strong physio-chemical reactions, leading to a series of formation of compounds, including iron-aluminium-silicon intermetallic materials on the steel surface [29]. Identical cross-sections were evaluated using optical microscope, followed by crack and cavity image analysis. Statistics were used to analyse three distinct parts of the cross-section of each sample. Though additional measurements were utilized to refine statistical analysis, the initial crack and cavity parameters can be obtained. The crack length and average crack length were obtained as the ratio of crack number to length of analysed surface part (Figs. 7 and 8). Both crack lengths and average crack length were significantly constrained $(<100 \mu \mathrm{m})$, but those of the oxidized samples were a bit higher.

Cavity density was a bit higher in samples after thermal fatigue immersion and largely higher compared with crack densities. Such observations are still inconclu- sive; however, the results corresponded with those of qualitative analysis during periodic inspections and cyclic immersion and exposure. Nevertheless, the low penetration depth of cavities and cracks ensures that cyclic immersion does not adversely affect bulk steel in molten Al alloy. Moreover, the test results and microhardness evaluation indicated that the effect of softening was more significant than the initiation of each surface deterioration.

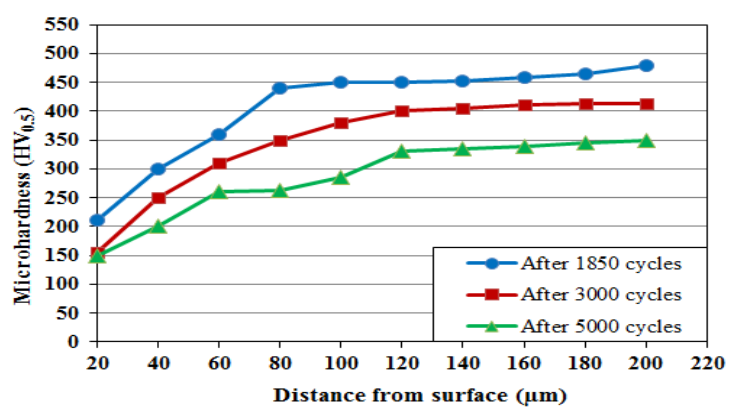

Fig. 6 Microhardness profiles before and during cyclic immersion in molten $\mathrm{Al}$ alloy

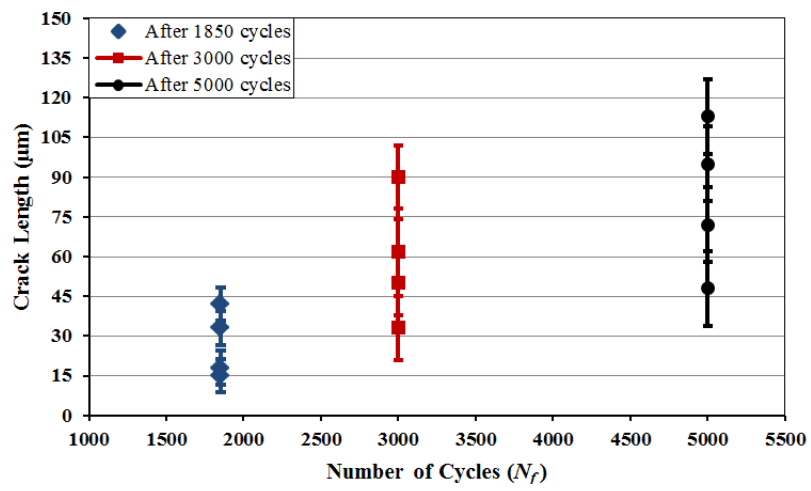

Fig. 7 Effect of cycle number on crack lengths

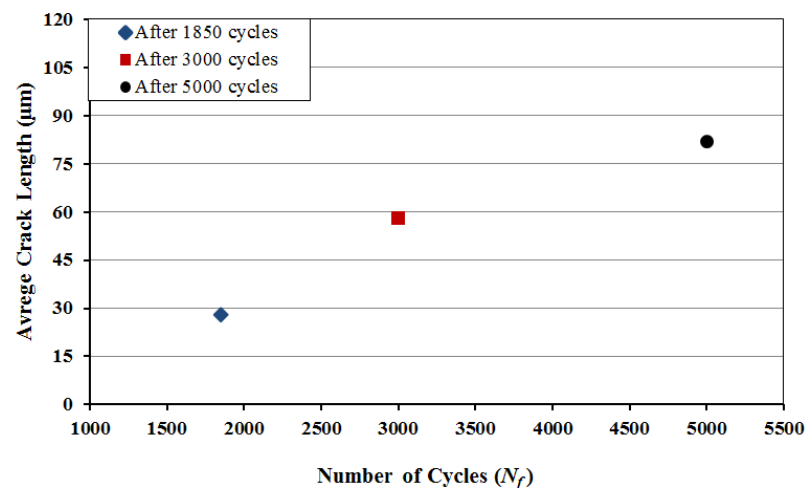

Fig. 8 Average crack lengths and cycle number

\section{Conclusions}

This paper first reports adhesion wear effects and heat fatigue in molten $\mathrm{Al}$ alloy during cyclic immersion tests. Light alloy die casting cycles were designed to simulate the mechanisms of die degradation. Laboratory tests were used in die casting cycles while a specially-developed process was used to test the nitride-, oxidized-, and heattreated samples. The heat-treated surface exhibited a large affinity for silicon and $\mathrm{Al}$; in this condition, adhesion first wear off. Contrarily, in the oxidized samples, the top hard oxide served as a barrier against soldering influence to protect the sub-surface and surface layers. The top oxide-compound layer also effectively protected the oxidized specimens after 3000 cycles. Exfoliating effects were observed 
between 3000-5000 immersion cycles; these effects gradually destroyed the oxide barrier, leaving potential metallic surface un-attacked by melting. More clearly, softening effect was detected and was remarkably observed with increasing toughness and decreasing microhardness along with immersion cycle number. Softening lowers core hardness and affects surface quality. Additionally, softening detrimentally influences service performance. Thus, on the surface, plastic deformation indicates termination of service. Oxidation limited this reduction in hardness and prevented the corrosion of metal surfaces (as barrier of aluminium invasion) in the first 3000 cycles. The developed test bench provided results similar to those currently available in the open literature. The temperatures recorded for the steel surface were similar to those measured on the actual large-production die casting.

\section{References}

1. Kusinski, J.; Kac, S.; Kopia, A.; Radziszewska, A.; Rozmus-Górnikowska, M.; Major, B.; Major, L.; Marczak, J.; Lisiecki, A. 2012. Laser modification of the materials surface layer-a review paper, Bulletin of the Polish Academy of Sciences: Technical Sciences 60: 711-728.

2. Abdulhadi, H.; Ahmad, S.; Ismail, I.; Ishak, M.; Mohammed, G. R. 2017. Thermally-induced crack evaluation in H13 tool steel, Metals 7: 475. http://doi.org:10.3390/met7110475.

3. Klobčar, D.; Kosec, L.; Kosec, B.; Tušek, J. 2012. Thermo fatigue cracking of die casting dies, Engineering failure analysis 20: 43-53. https://doi.org/10.1016/j.engfailanal.2011.10.005.

4. Tong, X.; Dai, M. J.; Zhang, Z. H. 2013. Thermal fatigue resistance of $\mathrm{H} 13$ steel treated by selective laser surface melting and CrNi alloying, Applied Surface Science 271: 373-380.

https://doi.org/10.1016/j.apsusc.2013.01.209.

5. Abdelatif, A. O.; Owen, J.S.; Hussein, M. F. M. 2015. Modelling the pre stress transfer in pre-tensioned concrete elements, Finite Elements in Analysis and Design 94: 47-63. https://doi.org/10.1016/j.finel.2014.09.007.

6. Ghiotti, A.; Bruschi, S.; Sgarabotto, F.; Bariani, P. F. 2014. Tribological performances of Zn-based coating in direct hot stamping, Tribology International 78: 142151. https://doi.org/10.1016/j.triboint.2014.05.007.

7. Ji, S. X.; Jiang, B.; Yang, W. C.; Fan, Z. Y. 2013. Melt quenched high pressure die casting (MQ-HPDC) of an A356 alloy, Materials Science Forum 765: 195-199. https://doi.org/10.4028/www.scientific.net/MSF.765.195.

8. Hsu, Q. C.; Do, A. T. 2013. Minimum porosity formation in pressure dies casting by Taguchi method, Mathematical Problems in Engineering, p. 1-9. http://dx.doi.org/10.1155/2013/920865.

9. Aweda, J. O.; Adeyemi, M. B. 2009. Experimental determination of heat transfer coefficients during squeeze casting of aluminium, Journal of Materials Processing Technology 209(3): 1477-1483.

https://doi.org/10.1016/j.jmatprotec.2008.03.071.

10. Chen, C. 2016. Fatigue life assessment of thermal cracked dies and moulds for remanufacturing, University of Nottingham.

http://eprints.nottingham.ac.uk/id/eprint/31389.

11. Okazaki, Y. 2012. Comparison of fatigue properties and fatigue crack growth rates of various implantable metals, Materials 5(12): 2981-3005.

https://doi.org/10.3390/ma5122981.

12. Alimi, A.; Fajoui, J.; Kchaou, M.; Branchu, S.; Elleuch, R.; Jacquemin, F. 2016. Multi-scale hot working tool damage (X40CrMoV5-1) analysis in relation to the forging process, Engineering Failure Analysis 62: 142155 . https://doi.org/10.1016/j.engfailanal.2015.11.031.

13. Taljat, B.; Tušek, J.; Klobcar, D.; Boscarol, P.; Scavino, G. 2002. Heat and surface treatment of hotwork tool steel for optimum in-service performance, Proceedings of the 6th International Tooling Conference on the Use of Tool Steels: Experience and Research, Karlstad University, Sweden.

14. Ghusoon, R. M.; Rawaa, H. M.; Basim, H. A. 2019. Effect of die geometry on thermal fatigue of tool steel in aluminium alloy die-casting, IOP Conference Series: Materials Science and Engineering 518: 032042. http://dx.doi.org/10.1088/1757-899X/518/3/032042.

15. Kleiner, M.; Geiger, M.; Klaus, A. 2003. Manufacturing of lightweight components by metal forming, CIRP Annals-Manufacturing Technology 52(2): 521-542. https://doi.org/10.1016/S0007-8506(07)60202-9.

16. Pastor, A.; Valles, P.; Amurrio, I.; Medina, S. F. 2015. Heat treatment conditions to prevent failure in die cast X38CrMoV5 steel parts, Engineering Failure Analysis 56: 520-529. https://doi.org/10.1016/j.engfailanal.2014.11.016.

17. Srivastava, A.; Joshi, V.; Shivpuri, R. 2002. Numerical models and their validity in the prediction of heat checking in die casting tooling, 6th International Tooling Conference.

18. Klobčar, D.; Tušek, J.; Taljat, B. 2008. Thermal fatigue of materials for die-casting tooling, Materials Science and Engineering A, 472(1-2): 198-207. https://doi.org/10.1016/j.msea.2007.03.025.

19. Naimi, S.; Hosseini, S. M. 2015. Tool steels in die-casting utilization and increased mold life, Advances in Mechanical Engineering 7(1): 286071. https://journals.sagepub.com/doi/abs/10.1155/2014/286071.

20. Medjedoub, F.; Le Roux, S.; Dour, G; Rézaï-Aria, F. 2014. Effect of local stress on the heat-checking morphology in high temperature tool steels under thermal fatigue: Transition from multi-axiality to uniaxiality, Mechanics of Materials 69(1): 159-172. https://doi.org/10.1016/j.mechmat.2013.09.014.

21. Muhič, M.; Kosel, F.; Pukšič, A.; Klobčar, D. 2011. A new approach to monitoring thermal fatigue cracks in die casting moulds, International Journal of Materials Research 102:69-75. https://doi.org/10.3139/146.110444.

22. Chen, C.; Wang, Y.; Ou, H.; Lin, Y-J. 2016. Energybased approach to thermal fatigue life of tool steels for die casting dies, International Journal of Fatigue 92: 166-178. https://doi.org/10.1016/j.ijfatigue.2016.06.016.

23. Lind, C. 2012. Two decades of negative thermal expansion research: where do we stand?, Materials 5(12): 
$1125-1154$ https://doi.org/10.3390/ma5061125.

24. Jia, Z. X.; Liu, Y. W.; Li, J. Q.; Liu, L. J.; Li, H. I. 2015. Crack growth behavior at thermal fatigue of H13 tool steel processed by laser surface melting, International Journal of Fatigue 78: 61-71. https://doi.org/10.1016/j.ijfatigue.2015.04.005.

25. Olofsson, J.; Svensson, I. L.; Lava, P.; Debruyne, D. 2014. Characterisation and investigation of local variations in mechanical behaviour in cast aluminium using gradient solidification, Digital Image Correlation and finite element simulation, Materials \& Design 56: 755762. https://doi.org/10.1016/j.matdes.2013.12.036.

26. Le Roux, S.; Medjedoub, F.; Dour, G.; Rézaï-Aria, F. 2013. Role of heat-flux density and mechanical loading on the microscopic heat-checking of high temperature tool steels under thermal fatigue experiments, International Journal of Fatigue 51: 15-25.

https://doi.org/10.1016/j.ijfatigue.2013.02.004.

27. Schwam, D.; Wallace, J.F.; Birceanu, S.; Efficiency, E.; Energy, R. 2004. Effect of design factors on thermal fatigue cracking of die casting dies. Work Performed Under Contract DE-FC07-00ID138486, US Department of Energy Assistant Secretary for Energy Efficiency and Renewable Energy, Washington, DC.

28. Srivastava, A.; Joshi, V.; Shivpuri, R. 2004. Computer modeling and prediction of thermal fatigue cracking in die-casting tooling, Wear 256(1): 38-43. https://doi.org/10.1016/S0043-1648 (03)00281-3.

29. Barrau, O.; Boher, C.; Vergne, C.; Rezai-Aria, F.; Gras, R. 2002. Investigations of friction and wear mechanisms of hot forging tool steels. Karlstad University, 1: p. 81-94.
G. R. Mohammed, E. M. Mubarak, B. H. Abbas

\section{THERMAL FATIGUE MODEL OF ALUMINIUM ALLOY DIE CASTING H-13 DIES UNDER THERMO- MECHANICAL CYCLE}

S u m m a r y

In industrial fields, thermal fatigue behavior has recently acquired an important role which is mainly related to the interaction between mechanical and thermal conditions. This paper proposes a thermal fatigue model of $\mathrm{H} 13$ tool steel under thermos-mechanical cycles. A test apparatus was used to assess the thermal fatigue resistance of materials to estimate surface crack area when specimens are subjected to thermal cycling. Thermal cycling up to $700^{\circ} \mathrm{C}$ was used, and crack patterns were examined after 1850, 3000, and 5000 cycles. Temperature distributions were measured at different locations in the test specimens. A model was developed to establish a relationship between mechanical cycling and thermal analysis. From the results, the thermal fatigue resistance was significantly improved over the control parameter after heating and cooling during thermomechanical cycles. The model was applied to determine the best performance and in-service life of die casting tools.

Keywords: die casting, thermal fatigue, thermo mechanical cycle.

Received April 11, 2020

Accepted October 04, 2021

This article is an Open Access article distributed under the terms and conditions of the Creative Commons Attribution 4.0 (CC BY 4.0) License (http://creativecommons.org/licenses/by/4.0/). 